\section{Brand 2020. El futuro de las marcas}

Andrea Pol *

Resumen: Para las grandes empresas y las marcas líderes actuales, el año 2020 ya es el futuro cercano, en términos estratégicos y tendenciales.

En vistas del nuevo decenio, consideramos que el valor gerencial determinante, a la hora de "gestar y gestionar una marca" con eficiencia, no es de carácter meramente cognitivo sino actitudinal; el rol del brand manager ha sufrido un inédito desplazamiento, desde el tradicional gerente de marca, hacia una especie de brand trend hunter-o cazador de tendencias de marca- que monitorea el mercado de manera creativa y holística.

Abordamos la construcción de un mapa de escenarios tendenciales para las marcas 2020, a partir de un encadenamiento de fenómenos significativos y características reveladoras de nuestro futuro cercano, en materia de branding.

Palabras clave: branding - prospectiva - gestión marcaria - brand trend hunter - marcas escenarios tendenciales - insight.

[Resúmenes en inglés y portugués en las páginas 120-121]

${ }^{(*)}$ Licenciada en Publicidad (Universidad Nacional de Lomas de Zamora). Postgrado de Actualización en marketing Estratégico (UNLZ). Profesora de Enseñanza Primaria (Escuela Normal Superior No 11). Docente de las áreas de publicidad, diseño y marketing en universidades e Instituciones terciarias. Actualmente tiene su estudio profesional -Andrea Pol Branding Simbólico- especializado en diseño de identidad visual, imagen corporativa e informe de evaluación de marcas.

"Pues si vemos lo presente como en un punto se es ido e acabado, si juzgamos sabiamente, daremos lo non venido por pasado"... (Manrique, 2002)

Ya en el siglo XV, el poeta Jorge Manrique expresó, con hondo dramatismo, la fugacidad del tiempo en sus Coplas por la muerte de su padre.

La fugacidad del tiempo parece ser más breve en nuestro presente. Las distancias- espaciales y temporales- se acortan, en una época signada por la inmediatez.

La proximidad de la información y los vínculos en Internet, re-significan para nosotros los alcances de lo contiguo y lo cercano.

Aunque la virtualización es un término que aparece en la década de los 60, aún hoy es un concepto ambiguo e indeterminado. 
En nuestra cosmovisión, lo virtual contiene en sí mismo la idea de un espacio sin tiempo. Y es quizás por esta misma dinámica actual de la información que, tratar de perfilar un escenario para las marcas en el 2020, se nos antoja una tarea posible, o al menos verosímil. Mucho se habla del futuro del branding y de las marcas. Para las grandes empresas y las marcas líderes actuales, el año 2020 ya es el futuro cercano, en términos estratégicos y tendenciales.

En estas líneas se intenta construir un mapa de escenarios tendenciales para las marcas del próximo decenio, a partir de un encadenamiento de fenómenos significativos y características reveladoras de nuestro futuro cercano, en materia de branding.

\section{Tendencias en branding}

Deducir tendencias futuras, a partir de una serie de datos disponibles hoy: menuda tarea. La detección de tendencias implica investigar en profundidad el mercado para identificar información relevante, traducida a posteriori en directrices estratégicas para la empresa y la marca.

¿Qué se entiende por información relevante en branding?

El conocimiento del consumidor y del mercado, tradicionalmente constituyeron los pilares para la planificación y la toma de decisiones. Hoy la búsqueda de información en sí misma, ya no es el principal elemento relevante para diseñar una estrategia de branding. Lo que representa un factor clave a nivel estratégico, es la capacidad de anticipar y reconocer el mercado a partir de esos datos: la detección de aquellos cambios sociales y culturales, generadores de nuevos hábitos y estilos de vida, que incidirán en nuevas tendencias de consumo.

En vistas del nuevo decenio, consideramos que el valor gerencial determinante, a la hora de "gestar y gestionar una marca" con eficiencia, no es de carácter meramente cognitivo sino actitudinal; el rol del brand manager ha sufrido un inédito desplazamiento, desde el tradicional gerente de marca, hacia una especie de brand trend hunter-o cazador de tendencias de marca- que monitorea el mercado de manera creativa y holística.

En la actualidad, los insight existentes en el germen de los fenómenos sociales emergentes constituyen los factores clave del branding estratégico.

Es pertinente señalar que en este contexto discursivo, "emergente" y "dominante" son dos polos opuestos en los escenarios tendenciales. En este sentido, anticipar una tendencia equivale a pre-ver, es decir "ver antes que": advertir una directriz de consumo emergente antes de que ésta sea dominante.

El futuro es siempre inquietante, pero quizás lo que más nos conmueve de él es la certeza del cambio venidero.

La actitud frente al cambio es lo que diferencia a los hombres conservadores de los innovadores. Lo único permanente es el cambio.

Ya lo expresaba el filósofo griego presocrático Heráclito de Éfeso:

Es imposible bañarse dos veces en el mismo río. (frag. 91) Descendemos y no descendemos a un mismo río; nosotros mismos somos y no somos. 
(frag. 49). A quien desciende a los mismos ríos, le alcanzan continuamente nuevas y nuevas aguas. (frag. 12) (Obiols, 1985, p. 242)

Efectivamente, es imposible bañarse dos veces en el mismo río: porque el río cambia y porque también nosotros ya no somos los mismos. La realidad está sometida a un cambio continuo, todo fluye y nada permanece estático. Esto, que resultaba evidente para Heráclito en su contemplación del mundo, es actualmente para nosotros un axioma vital que tiñe lo cotidiano.

En el mundo contemporáneo, subyace la perspectiva heraclítea del cambio; vivimos en una realidad caracterizada por la inmediatez y la vertiginosidad.

En el mundo on line y off line, todo parece surgir y extinguirse casi en el mismo acto.

Si el cambio permanente es la lógica intrínseca de "nuestro universo", la visión del futuro indefectiblemente nos con-mueve. Nos moviliza pensar que el "orden provisorio" de las cosas que nos rodean, será distinto a corto o mediano plazo. Y las marcas no escapan a esta dinámica.

La complejidad del fenómeno que nos ocupa, deriva de dos factores: la marca como objeto de estudio es multifacético y a la vez, inestable.

En respuesta a esta realidad compleja, distintas disciplinas y saberes heterogéneos intentan dar cuenta del fenómeno marcario en la actualidad.

En materia de branding, el enfoque holístico a través del conocimiento multidisciplinario, es una tendencia, que seguramente permanecerá por décadas. La marca es abordada desde la antropología, la psicología, la lingüística, la sociología, la semiótica, la semiología, la fonética, la fonología, la comunicación, el diseño, el arte, la arquitectura, la publicidad, el marketing, las neurociencias, etc.

Multiplicidad de teorías confluyen, en el afán de explicar la marca y sus diversos aspectos concomitantes. Si la realidad es fragmentada, multifacética y en un punto, caótica, los distintos saberes se aproximan a ella, aportando cierto orden racional, al menos de manera provisoria. Esta necesidad de ordenamiento responde a criterios prácticos; como afirma Gustavo Valdés de León:

Partiendo de concepciones comunes - no existen maneras ciertas de conocer la realidad- se afirma que, no obstante, se pueden llegar a conocer fragmentos observables de ella. (...)

Las teorías son, pues, "ficciones útiles", instrumentos que no dicen nada acerca de la realidad pero permiten operar pragmáticamente sobre ella y predecir sucesos futuros. Una teoría será "mejor" o, si prefiere "más verdadera", en la medida en que permita obtener mejores resultados prácticos. (Valdés de León, 2010, p. 21)

Las distintas teorizaciones acerca de la marca y el branding son "ficciones útiles" -definiciones provisorias y perfectibles- pero que explican el fenómeno en un momento y un contexto determinados, y en esto radica su importancia.

Nuevas herramientas de exploración, análisis y planeamiento estratégico, amplían el horizonte de conocimiento de la marca como fenómeno y la re-significan de manera continua. 
Desde la perspectiva de Marcelo Ghio:

En la sociedad contemporánea, el marco simbólico constituido por ese universo marcario impacta y deja huella en nuestra cotidianeidad. Las marcas se han convertido en un fenómeno comunicacional y comercial en una escala nunca antes alcanzada en la historia, trascendiendo y manifestándose como un activo componente de la cultura (...) Del mismo modo, la gestión de marcas ha requerido la elaboración de estructuras organizadas capaces de adecuarlas a los nuevos escenarios que la dinámica social y el mercado de consumo configuran. (Ghio, 2009, p. 16-17)

Actualmente, el universo marcario al que alude Ghio se conecta estratégicamente a la cotidianeidad del consumidor. Una de las más atractivas metodologías de estudio en branding es la etnografía. Marcas líderes como Movistar, Intel, Unilever, Nestlé, AT\&T, entre otras, la emplean en distintas áreas de negocios, planificación e innovación estratégica. Al respecto, cabe aclarar que se trata de un método de investigación, ampliamente usado en Antropología Cultural desde hace varias décadas, si bien es reciente su aplicación en el campo del branding. Los estudios etnográficos integran el contexto cotidiano -mediato e inmediatodel consumidor en la exploración y observación. La etnografía recorre un camino interesante de exploración de la marca, pues potencia la comprensión de nuevas relaciones y cuestiones emergentes, a la vez que contribuye a definir la experiencia marcaria.

Marketing de la experiencia, marketing relacional, marketing sensorial, branding emocional: hoy la marca es también experiencia y percepción, una emoción claramente identificada y diferenciada.

Dotada de la capacidad de conmover, la marca emociona. Ghio da cuenta de la excitación y el cambio químico que se produce cuando experimentamos una marca, con la introducción de un neologismo: oxitobrands. (Ghio, 2009)

El neuromarketing entiende el comportamiento del cerebro, en cuanto a sus reacciones frente a una marca. Las neurociencias aplicadas, ponen bajo la lupa los alcances actuales del concepto acuñado por Trout y Ries en los años sesenta: el posicionamiento.

Hoy, el brand management implica "gerenciar la mente de los consumidores". El desafío entonces, es re-conocer el terreno del posicionamiento: la mente humana.

Cerebro, neuronas, sinapsis, actividad neuronal, hormonas... el branding explora terrenos vírgenes del fenómeno marcario, de la mano de las neurociencias.

De cara al futuro, las marcas de hoy promueven seguidores y fans, ya no basta con captar, mantener y fidelizar consumidores o clientes.

Marcas como Apple se instalan netamente en un nivel diferente. Estudios de neuromarketing explican que la categoría en que un usuario "sitúa cerebralmente" a Apple es la religiosidad, en tal sentido, la marca no tiene usuarios, sino fieles.

Resulta evidente que la relación marca-usuario adopta modalidades distintas.

Las marcas top of mind constituyen una especie de "nueva religión”. Fervor, culto, adoración, devoción, todo esto puede inspirar una marca, conquistadora de partidarios y seguidores. La pulsión gregaria del hombre actual encuentra quizás su expresión "más fiel” en la marcas. 
El supuesto básico subyacente en esta perspectiva de análisis, es que los usuarios son personas de fe, "creyentes" que deben adherir y apoyar la "moción de la marca", por ejemplo mediante un click.

Según esta perspectiva, el gran desafío del branding actual es "catequizar" a los consumidores. Y puede hallarse bastante coherencia en esta afirmación, si nos remitimos a la etimología del término "fidelizar", derivado de la expresión latina fide: fe.

Hacer branding hoy, es generar fe en la marca. Encender el fervor de los seguidores y sostener ese compromiso.

Capaces de despertar una especie de fanatismo religioso, las grandes marcas se ubican cada vez más alto en la escalera del posicionamiento. Y que una marca se sitúe a nivel simbólico, en el plano de las utopías, los ideales, la religión, la fantasía, revela un giro estratégico en el campo del branding.

\section{Prospectiva y branding. Aprehender el futuro: una tarea posible}

El intento de abordar el futuro, a partir de una especie de narración creativa e imaginativa, y por ende arbitraria, en términos científicos, solo se aproxima a la mera elaboración hipotética acerca de la evolución de los sucesos o indicios presentes.

Lejos de abordar el futuro por el camino de la profecía, el branding cuenta con herramientas de análisis y planificación estratégica que permiten pre-ver, identificar, comprender y pro-yectar los cambios sociales relevantes, que se convertirán en directrices en materia de consumo y de comunicación de marca.

Por esta vía, se promueve la innovación, la investigación y el desarrollo, para el diseño de nuevas marcas y la detección de nuevas oportunidades de negocio.

En branding, para adelantarnos en el tiempo o venir del futuro hacia el presente, existen distintas herramientas de investigación y planeamiento: a la arquitectura de escenarios, y las técnicas de proferencia y prospectiva, les encomendamos la tarea estratégica de aprehender el futuro.

\section{Un mapa de escenarios tendenciales para las marcas en el año 2020}

El mapping del escenario de las marcas en el próximo decenio no puede escindirse del macro-contexto social, económico, demográfico, ecológico, político, climático, etc. Las variables incontrolables el macro entorno influyen indefectiblemente en toda estrategia de branding. En este sentido, el análisis de Global Trends 2025: A transformed world (Tendencias globales 2025: un mundo transformado) revela el advenimiento de un mundo multipolar y describe tres escenarios posibles al promediar la tercera década del nuevo milenio.

Este informe de prospectiva del NIC -el Consejo Nacional de Inteligencia de EEUU- se basa en la implementación de la metodología de escenarios, por lo que cada situación tendencial descripta no es categórica, sino que expresa tres ópticas distintas para un mismo evento temporal (año 2025). El desempeño competitivo de las marcas en el seno de este nuevo mundo transformado, constituye sin lugar a dudas, un desafío estratégico. El 
horizonte del branding puede ser planteado con alto grado de certidumbre, en función de instrumentar los mecanismos de análisis prospectivo y establecer el impacto de los cambios en la gestación y gestión de marcas.

A partir de una serie de fenómenos significativos y características reveladoras de nuestro futuro cercano, se propone un mapa de escenarios tendenciales para las marcas en el año 2020:

\section{Las grandes marcas de hoy probablemente seguirán siendo las grandes marcas del año 2020}

El know- how y el liderazgo en materia de branding estratégico, constituyen los seguros de vida que cubren la supervivencia de una marca.

Por eso, consideramos que, de la interacción particular de cuatro factores, dependerá el significado de una marca en el futuro: Popularidad: Coca-Cola, Apple, Mc Donald's seguirán ocupando la parte superior de la pirámide de las principales marcas mundiales en su mercado. Medios y nuevas tecnologías: las vías privilegiadas de comunicación e interacción con los consumidores, en función de las nuevas técnicas emergentes. Cambios en el consumidor: son relevantes para el branding aquellas tendencias sociales que impacten en los hábitos de consumo y el uso de los medios Hábitos de consumo: anticipar la modalidad de estos cambios, y su dinámica interna, en tanto generadores de nuevos hábitos.

Tecnología: existen varias consultoras globales de nuevas tecnologías, que detectan tendencias a nivel mundial. Por ejemplo, Gartner Group (www.gartner.com) líder en technology research, investiga no solo el impacto en los años siguientes, sino que traduce esta información en insight, para generar nuevas oportunidades de negocios, derivadas de estos cambios.

Velocidad: la innovación en el terreno del branding se acelerará aún más en la próxima década, en función de la profundización de los cambios, que hoy se perfilan en el mapa de las tendencias globales.

Plasticidad e Innovación estratégica: frente a los cambios y la velocidad de los mismos, las empresas y marcas que se adaptan con flexibilidad, lideran el camino de la innovación y son capaces de generar espacios sin competencia, surfeando las aguas de un "océano azul" con verdaderas posibilidades de crecimiento. (Kim y Mauborgne, 2005)

En el año 2020, las "marcas plásticas" se adaptan con versatilidad y eficiencia al entorno cambiante, intentando -al menos de manera temporaria y efímera- suavizar la mutabilidad reinante con su constancia provisoria.

¿Qué parámetros le permiten a la marca generar cierto nivel de permanencia y estabilidad, en este contexto?

La marca debe ser entendida como un sistema abierto: el cambio no amenaza ni pone en riesgo la vitalidad marcaria; por el contrario, es una condición estructural e inherente de 
su propia naturaleza. El anquilosamiento, la inmovilidad y el estancamiento, no condicen con la gestión de branding actual. Intrínsecamente el concepto de innovación conlleva un nivel de riesgo que las grandes marcas están dispuestas a asumir.

Arquitectura de las marcas: los pilares desde los cuales se construyen las marcas sólidas del futuro están representados por el servicio, el diseño y la experiencia. La planificación, la investigación y el diseño de una estrategia de marca permiten consolidar un espacio de vinculación con los usuarios en el tiempo.

La palabra fidelidad proviene del latín fide, que significa fe. En cuanto a las marcas se refiere, solo si se mantiene una interacción sostenida con los usuarios en el tiempo, es factible hablar de fidelización. El desafío de las marcas pasa por sustentar y alimentar esta re-elección en el tiempo. En la actualidad, el combustible que insufla energía en este vínculo es la emoción.

Interactividad: más allá de la tecnología específica que permita en el futuro generar espacios de vinculación con la marca, y de los nuevos medios de comunicación emergentes, la capacidad de inter-actuar con los usuarios crecerá exponencialmente; las marcas sociales ya son una tendencia dominante en materia de branding.

Servicio: los nuevos proyectos de desarrollo marcario tienden a aumentar el valor a partir del diseño de servicios- o más aún, del diseño de una experiencia del servicio- despegando la promesa de marca del nivel cercano, o de lo que podríamos definir como "marca esperada", para trascender incluso las propias expectativas del cliente.

Personalización: Partir de la existencia de una personalidad de la marca, supone reconocer el mecanismo de proyección implícito, según el cual la empresa pro-yecta en la marca sus valores, su cultura, su filosofía corporativa y sus atributos diferenciales; definir su particular fisonomía permite que los consumidores puedan establecer un vínculo de identificación y empatía con la promesa de la marca.

Identificación y proyección son los mecanismos simbólicos que adoptan las marcas y empresas, como así también el público consumidor, en función de construir una identidad de marca diferenciadora.

Los consumidores establecen una analogía entre las personas y las marcas, las que resultan "humanizadas". Este es el credo del Branding emocional. Wilensky afirma que las marcas se personalizan porque despiertan emociones y pasiones humanas, a la vez que define la identidad marcaria como:

El resultado de un proceso complejo, inconsciente y dialéctico (...) Si bien la marca es construida por la empresa, desde su origen mismo es concebida pensando en el consumidor. Además el consumidor "completa" la identidad de la marca construyéndola con sus propias imágenes y motivaciones. (Wilensky, 2003, p. 111) 
Wilensky plantea entonces la identidad de la marca en términos de una relación dialéctica entre ésta y el consumidor, en la cual se genera un juego simbólico bidireccional.

Después de la Segunda Guerra Mundial, el concepto y la razón de ser del Diseño gráfico experimentan nuevas variaciones.

En el centro de un complejo proceso entre la industria y el mundo exterior, las relaciones públicas usan del diseño como parte del negocio desde los papeles de oficina a la publicidad impresa, de las oficinas a los muebles, la dirección artística trata de dotar de personalidad visual cualquier detalle susceptible de producir un efecto más favorable en toda la gestión de la empresa, tanto de carácter interno como externo. (Bayer, 1994, p. 272)

En este párrafo subyace un concepto interesante a la hora de diseñar, ya sea una marca o un sistema de identificación completo: la personalidad visual. Bayer deja entrever que, más allá de los particulares soportes donde la marca se plasma, la unidad conceptual y simbólica, reside en la personalidad visual, que actúa como el hilo conductor de las múltiples manifestaciones de la marca.

En el seno de la Psicología, el concepto de personalidad hace referencia a una organización dinámica, que designa al conjunto de características de una persona. Hay dos aspectos inherentes al concepto de personalidad: distinción (diferencia entre un individuo de otro) y persistencia (constancia, permanencia y congruencia del comportamiento, que mantiene relativamente estable la personalidad, a través del tiempo). Ambos aspectos resultan de vital importancia en el proceso de construcción de la identidad.

Análoga situación se presenta en el diseño de identidad de la marca, que a través de sus símbolos gráficos, espaciales, cromáticos y fonéticos, refleja de manera persistente la personalidad de la marca (Pol, 2005). Dichos rasgos se integran en una unidad coherente, y son sintetizados en la personalidad. En términos de Guillaume: "La personalidad posee una unidad (si se la considera en un momento dado de su existencia) y una identidad (si se la considera en su duración). (Guillaume, 1964, p. 265)

En este devenir del concepto y los alcances del diseño, se registra en los años '80 un mayor énfasis en la gestión de la identidad corporativa y el monitoreo de la imagen de marca. Ledesma establece la manera activa en que el diseño gráfico ha colaborado en la constitución de los imaginarios contemporáneos:

Ha contribuido a delinear el objeto de consumo y, más adelante, a reubicarlo, convirtiendo al logo (y la imagen que representa) en el nuevo 'objeto de consumo' (Klein: 2002). En sus expresiones publicitarias y empresariales, en su vinculación con la mercadotecnia y la estética del consumo, el diseño gráfico penetró en la corteza de la realidad convirtiéndose en un factor potente dentro del proceso de producción, distribución y consumo. (Ledesma, 2003, pp. 50-51)

El diseñador al crear la identidad visual de una marca, establece un diálogo simbólico con el consumidor. Este hombre pro-medio busca permanentemente identificarse con un 
'otro', sea una idea, un grupo, una marca; es propenso a integrarse y con-fundirse con un grupo social. Ledesma plantea que la acción del diseño gráfico "no se reduce a transformar los datos en un hecho visible sino que al diseñar, diseña los modos en que ese hecho visible será apropiado por el ojo. Este ojo tan lleno de historia, tan saturado de imágenes..." (Ledesma, 2003, p. 81)

La interpretación del hecho visible, y podría añadirse del hecho auditivo, responde en el consumidor a factores conscientes e inconscientes. Esas imágenes, percibidas por el "ojo lleno de historia" actúan como links permanentes a contenidos más profundos y remotos, que son descifrados por el público, aún de manera indeliberada.

De tal modo, el estímulo visual y auditivo que es la marca para el público, reviste un doble nivel de análisis; por un lado, los aspectos conscientes de la misma, que el consumidor puede percibir e incluso verbalizar a nivel reflexivo (nombre, formas, colores, trazos, tipografía, etc.) y por otro, los factores inconscientes que suman una valoración adicional a estos elementos (símbolos gráficos, espaciales, cromáticos y fonéticos) presentes sinérgicamente en su estructura visual y auditiva. (Pol, 2005)

En el branding 2020, las marcas redoblan la apuesta mediante la personalización de la información destinada al usuario. En función de las nuevas tecnologías, la tendencia hacia la búsqueda de información diferenciada, posibilita la aplicación del marketing one to one, con el objeto de proponer al usuario un mensaje singularizado, que optimice su eficacia a través del grado de proximidad a sus intereses, actitudes, estilo de vida, modalidad de uso de los medios, etc.

\section{Decálogo del Branding 2020}

¿Qué características tendrán las marcas del futuro?

¿Qué lineamientos estratégicos adoptará la gestación y gestión de branding en el año 2020? La pirámide representa las nueve características tendenciales que, a nuestro criterio, definen el desempeño de las marcas en el próximo decenio:

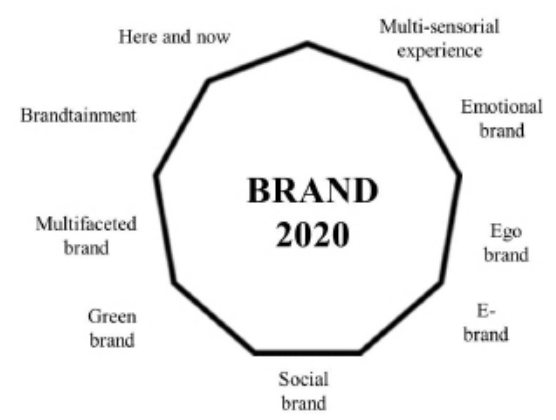

Figura 1. Brand 2020. Características tendenciales de las marcas en el próximo decenio. Fuente: elaboración propia. 


\section{Social Brand}

Irene Cano directora comercial de Facebook España afirma que "En el futuro todas las marcas serán sociales". (Cano, 2012)

Por definición, toda marca es social. Cobra su razón de ser en el seno de una comunidad o grupo. En tal sentido, la construcción social de la marca se genera a partir de la colaboración y los aportes de múltiples usuarios. El branding 2020 implica la gestión de esta dinámica de inter-acción colectiva, y de sus particulares modalidades de monitoreo.

El contrato que los seguidores establecen con la marca a través de una red social involucra aristas aún desconocidas; desde el branding, esto plantea renovados desafíos para las marcas, como generadoras de nuevos espacios de interactividad.

Facebook reformula, no solo la manera de relacionarse y comunicarse con los usuarios, sino también las posibilidades de intercambio y la transacción misma con los clientes.

Lo que probablemente está diciendo Cano, es que la presencia de las marcas en las redes sociales mantendrá una tendencia creciente.

\section{Lo que Facebook ha unido, que no lo separe la segmentación}

En Facebook, el liderazgo de la marca encuentra como nunca antes su correlato discursivo: actualmente, las marcas ya no tienen consumidores o usuarios sino "seguidores" o "fans". Adeptos, partidarios, admiradores o apasionados. Fieles, devotos, místicos de la marca. La marca es una especie de logia, cuyo rito de iniciación se resume en cliquear "Me gusta" Para unirse al grupo, y ser miembro de la mística de la marca, basta con un click.

Paradójicamente, en los últimos días se ha dado a conocer que Facebook empieza a registrar una tendencia decreciente, en función de la disminución en el número de usuarios que frecuentan esta red social:

Un estudio demuestra un claro retroceso en sus mayores mercados (EEUU, Canadá y Reino Unido), para acciones como actualizar su estado, compartir contenidos o enviar mensajes.

Los propios usuarios aseguran que la avalancha de mensajes publicitarios aburre, que las marcas hacen insoportable su uso, que prefieren hablar con personas y no con marcas, que ya no es la red social que era, que hay demasiados adultos (padres y demás familiares) (maspixel.com, 2014)

Otro artículo publicado en La Voz bajo el título Facebook pierde usuarios en EE.UU, Canadá y Reino Unido ya identificaba esta tendencia involutiva el año pasado:

Facebook registra una desaceleración en su crecimiento, apunta Europa Press. Uno de los motivos es la pérdida de usuarios en países clave. (...) En Estados Unidos, el volumen de usuarios pasó de 155.2 millones de usuarios a 149.4 millones, lo que significa un descenso de 5.8 millones. Otro país que perdió usuarios es Canadá. En este caso, el descenso es de 1,52 millones 
de usuarios. En Reino Unido y Noruega las pérdidas han sido de 100 mil conectados. (La Voz, 2011)

Los motivos aparentes son la falta de interés y la monotonía; la presencia de marcas y la publicidad en la red social son factores de descontento e insatisfacción en los usuarios más críticos. En tanto, América Latina continúa registrando un nivel de crecimiento relativamente estable; por ejemplo en Argentina la red social alcanza los 15,1 millones de usuarios.

\section{Here and Now}

Las marcas 2020, responden a la renovada necesidad de inmediatez de los consumidores. En el aquí y ahora, proporcionan satisfacción y gratificación instantánea, pero a la vez, fugaz. Acompañan con flexibilidad el complejo estilo de vida actual, sin perturbar su dinámica. Las nuevas tecnologías posibilitan esta conexión en cualquier momento y en todo lugar. El mobile marketing se perfila como una herramienta privilegiada de información, comunicación e interactividad con los usuarios. Con la llegada de los smartphones, crecen exponencialmente las posibilidades de establecer un vínculo marcario sólido y una experiencia significativa con los clientes en el aquí y ahora, minuto a minuto.

El manejo racional del tiempo, la gestión del ocio, el consumo inteligente y la necesidad de simplificar la vida cotidiana, son tendencias que demandan de las marcas, una mayor adaptación y plasticidad.

\section{e-Brand}

Es un hecho que las marcas actuales se desenvuelven en distintos ámbitos de actuación. El desempeño de una marca en Internet, excede la mera exhibición de su logotipo o el desarrollo de los contenidos de su web page; implica para la empresa, la capacidad de anticipación y gestión estratégica de los procesos, los eventos y sus derivaciones, en materia de branding. Incluso, muchas marcas solo tienen presencia en el entorno virtual.

El e-branding o gestión de la marca digital, contempla una multiplicidad de aspectos de la relación con los clientes, tendientes a generar una experiencia de usuario satisfactoria y una profunda conexión emocional.

Facebook, Twitter, Google+ y Linkedin son hoy los pilares de la construcción marcaria en los medios sociales. Pero, probablemente en el futuro cercano, mutarán hacia nuevas modalidades de interacción, o bien serán reemplazados por otras herramientas. Quizás, el motor que provoque este cambio está representado por la tendencia creciente a construir un vínculo personalizado, significativo e influyente con los usuarios, a través de la e-brand. En otra orientación, se encuentran quienes escapan de la directriz definida por la dominante tecnológica: los "tecnofóbicos" se resisten a los avances técnicos y no se integran a las redes sociales, constituyendo otro perfil netamente diferente. 
$\mathrm{Al}$ respecto, un artículo recientemente posteado por Gonzalo Vázquez en el Jot Down Cultural Magazine, titulado El imbécil digital, describe con renuencia los efectos que las nuevas redes sociales y los adelantos tecnológicos provocan en el individuo.

Aquí se reproduce un fragmento del texto que aparece en el referido magazine de cultura contemporánea:

Érase un hombre a una pantalla pegado, un hombre dirigido, un hombre conectado.

El iPhone dirige sus manos, el GPS su rumbo, Facebook sus ritmos, Twitter sus ojos, Whatsapp sus dedos, iPod sus oídos, iPad sus deseos, Tuenti sus hormonas y la Play sus ratos libres, los pocos que le deja un teclado.

Un hombre que dice estar conectado. Que no repara dónde ni cuándo ni por qué ni si era necesario. Un hombre que fue conectado sin que nadie le advirtiera que tal vez nadie habría más desconectado. Un hombre que empieza a olvidar oler y ser olido, tocar y ser tocado, lamer y ser lamido, oír y ser oído, ver y ser visto. Un hombre sumergido a cada vez mayor profundidad en un océano invisible. Que se complace en perder la carne y hueso. Un hombre que cree sentir libertad porque ha dejado de ver cables. Un hombre sin tiempo ni espacio. Un hombre igual, antes imbécil que digital. (Vázquez, 2012)

Las marcas del siguiente decenio probablemente encuentren más interlocutores tecnofílicos que tecnofóbicos entre los consumidores, pero no deja de resultar interesante que en el presente, aún conviven algunos quijotes de la cultura analógica, frente a los multitudinarios adeptos de las nuevas tendencias dominantes.

En tiempos en que la obsolescencia planificada continúa ganando por varios cuerpos al hiperconsumo, el hombre encuentra cierto sosiego efímero en la satisfacción personal que le brindan los productos y las marcas.

De algún modo, Vázquez pone en evidencia la paradoja del individuo hipermoderno; en la actualidad, son las marcas quienes parecen recordarle al hombre la importancia de "oler y ser olido, tocar y ser tocado, lamer y ser lamido, oír y ser oído, ver y ser visto” En el engranaje del branding actual (sensory branding, experiential branding, etc.) las emociones, las sensaciones y las experiencias mantienen aceitado el mecanismo del consumo y de la fidelidad marcaria.

\section{Emotional Brand}

Brand+Emotion: una relación con futuro. El branding se define aquí como la creación, desarrollo y mantenimiento de una marca en el mercado.

La emoción, la empatía y la generación de espacios vivenciales del consumidor con la marca son los pilares del branding 2020.

Marcelo Ghio, especialista en branding emocional, presenta la problemática en estos términos: 
¿Cómo explicar el vínculo afectivo, emocional y permanente que las marcas comparten con sus públicos?

Los aspectos emocionales, sostenidos y expresados a partir de vivencias y valores positivos, son el motor inicial de esa relación. Una idea de marca inspiradora es el punto de partida para la construcción de un vínculo poderoso. Pero eso no es todo. Las vivencias y valores compartidos constituyen la matriz del "diálogo" íntimo que la marca establece con cada individuo, proporcionando una base de confianza recíproca sobre la que se consolida ese vínculo. (Ghio, 2009, p. 18)

Como reza el título de la obra, el branding construye "marcas humanas para un mercado emocional". La edificación de un vínculo, a partir de la emoción y la confianza, genera una experiencia de marca positiva.

David Aaker define la identidad de la marca en estos términos:

Es un conjunto de asociaciones de la marca que el estratega de marca aspira a crear o mantener. Estas asociaciones implican una promesa a los clientes por los integrantes de la organización.

(...) Cuando se realiza, la identidad de marca debería establecer una relación entre la marca y el cliente, generando una proposición de valor que potencialmente involucre beneficios funcionales, emocionales o de autoexpresión o suministrando credibilidad a las marcas respaldadas. (Aaker, 2005, p. 59)

Un beneficio emocional apunta a la capacidad de la marca para provocar en el consumidor o usuario un sentimiento, devenido de su particular experiencia con ésta. Así, un cliente se siente seductor y atractivo con las mujeres si usa el desodorante Axe; se considera afectuoso y dulce, si regala un Bon-o-Bon durante la Semana de la Dulzura, o se siente actualizado y moderno si usa Blackberry.

Un beneficio de autoexpresión remite a la capacidad de la marca de convertirse en un vehículo que permite al consumidor pronunciar y expresar un perfil individual de autoimagen, vinculado a los múltiples roles que éste desempeña. En este sentido, comprar o usar una marca determinada se convierte en un medio privilegiado de satisfacer una necesidad autoexpresiva. Una persona expresa su camaradería, su amistad, cuando comparte una cerveza Quilmes en un encuentro entre amigos.

El sistema de identidad de la marca debe establecer y construir una reciprocidad estrecha con sus clientes, similar a la que se plantea en las relaciones interpersonales. De este modo, una marca puede ser madre (Lucchetti), amiga (Quilmes) o asistente (Mr. Músculo) desempeñando distintos roles (Aaker, 2005, p. 66) 


\section{Multi-sensorial experience}

El experiential branding propone activar los cinco sentidos de los consumidores o usuarios a través de la interacción con la marca en sus múltiples soportes de vinculación.

La experiencia de marca estimula sensaciones y emociones que pretenden con-mover al consumidor, para moldear sus preferencias, decisiones de compra, satisfacción y lealtad. El resultado es aumentar el brand equity o valor marcario.

La marca desde esta perspectiva de análisis, se convierte en el motor de imágenes sensuales. La promesa marcaria es traducida en un crisol de sensaciones visuales, olfativas, auditivas, táctiles y gustativas, que en branding se define como experiencia multi-sensorial. El merchandising es la técnica de comunicaciones integradas de marketing que por excelencia trabaja con la conexión sensorial en el punto de venta; entiéndase que éste puede ser físico o virtual, pues ya se manejan técnicas de e-merchandising para tiendas on line o espacios de vinculación marcaria en entornos digitales.

El sensory branding o branding sensorial se vale de aromas, videos, música, luces, colores, texturas, sabores y sonidos; hasta la temperatura media de un espacio comercial es portadora de significación. La sumatoria de estas sensaciones placenteras y estimulantes, busca que la marca persista en la memoria de manera espontánea y poderosa. En nuestro mercado, ya existen varias empresas de servicios proveedoras de experiencias integrales y sensoriales para las marcas.

\section{Ego Brand}

La cosmovisión del siglo XIX ya definía un nuevo hombre, caracterizado por una desmedida cantidad de apetencias, sujeto a la vez, a un amplio abanico de posibilidades, a la hora de satisfacerlas. Ortega y Gasset, en La rebelión de las masas, señala como rasgos dominantes de su carácter la "libre expansión de sus deseos vitales" (Ortega y Gasset, 1930, p. 57). En este mundo, el hombre no encuentra limitaciones a sus deseos, en ningún sentido, sino que el mismo entorno que lo rodea fomenta sus apetitos, llevándolos a un crecimiento indefinido.

Las ego brands proponen la autoexpresión individual, mediante la expansión de la propia identidad y la proyección de sus deseos, valores o aspiraciones a través de las marcas.

El individuo encuentra en la promesa marcaria el vehículo para la satisfacción de sus necesidades personales.

\section{Green Brand}

Otra característica tendencial de las marcas 2020 reside en la proliferación de las llamadas "marcas verdes".

De la mano del cuidado de la ecología y una mayor concientización acerca de las problemáticas ambientales, generadas por el impacto del hiperconsumo global, las green brands 
potencian la responsabilidad y el compromiso individual y social, a través de acciones sustentables.

Toyota, 3M, Siemens, Johnson \& Johnson y HP, encabezan el ranking 2011 de Interbrand, de las 50 marcas más verdes del mundo.

Salvo el caso de Toyota, que registra una regresión en la tabla, con una tendencia negativa del -7.64 con respecto al informe previo, realizado en el año 2010, la posición de las otras cuatro marcas líderes, expresa un creciente compromiso con la responsabilidad social corporativa y la persistente toma de decisiones estratégicas, en materia de cuidado del medio ambiente.

Por otra parte, el ranking de Interbrand indaga la percepción de los consumidores con respecto a las marcas; en esta edición resulta llamativo que McDonald's es una de las que más cayó, registrando un índice negativo del -27,96, lo que la lleva a ocupar el puesto $45^{\circ}$ del ranking Best Global Green Brands.

\section{Multifaceted Brand}

La complejidad del fenómeno que nos ocupa, deriva de dos factores: la marca como objeto de estudio es multifacético y a la vez, inestable.

En respuesta a esta realidad compleja, distintas disciplinas y saberes heterogéneos intentan dar cuenta del fenómeno marcario en la actualidad.

En materia de branding, el enfoque holístico a través del conocimiento multidisciplinario, es una tendencia, que seguramente permanecerá por décadas. La marca es abordada desde la antropología, la psicología, la lingüística, la sociología, la semiótica, la semiología, la fonética, la fonología, la comunicación, el diseño, el arte, la arquitectura, la publicidad, el marketing, las neurociencias, etc.

Multiplicidad de teorías confluyen, en el afán de explicar la marca y sus diversos aspectos concomitantes.

\section{Brand-tainment}

Probablemente, las marcas 2020 apunten a lograr una experiencia memorable y significativa a nivel individual y grupal. La revalorización de la dimensión lúdica-social las impulsa a establecer una mayor conexión emocional a través del entretenimiento, la diversión, el juego, la exaltación, la aventura y el asombro.

La re-creación del vínculo con los consumidores genera nuevos espacios de interacción para dar sustento a la promesa marcaria.

Brand-tainment es un neologismo que aquí se introduce -como síntesis de los vocablos brand (marca) y entertainment (entretenimiento)- para describir la marca-entretenimiento. La idea es que se asocie a la marca a un espacio de diversión, en un entorno expansivo de interacción mutua. En este sentido, el branding pretende establecer un link a una experiencia exclusiva y perdurable de alegría y bienestar. 


\section{Referencias Bibliográficas}

Aaker,D y Joachimsthaler, E. (2005) Liderazgo de Marca, Barcelona: Deusto.

Cano, I. (14 de febrero 2012). 7th annual Marketing Strategy Forum.. Ponencia (Disponible en http://www.marketingdirecto.com/marketing-directo-tv/ponencias/irene-canofacebook-espana-en-el-futuro-todas-las-marcas-seran-sociales/)

Gartner Group (www.gartner.com)

Ghio, M. (2009). Oxitobrands: marcas humanas para un mercado emocional, Buenos Aires: Graal.

Global Trends 2025: A transformed world (Tendencias globales 2025: un mundo transformado) disponible en http://www.dni.gov/nic/NIC_2025_project.html y http://www.dni. gov/nic/NIC_2025_global_scenarios.html

Guillaume, P. (1964). Manual de Psicología, (Volumen 2) Buenos Aires: Paidós.

Interbrand, (2011). Best Global Green Brands (Disponible en http://www.interbrand.com/ en/best-global-brands/Best-Global-Green-Brands/2011-Report/BestGlobalGreenBrands Table-2011.aspx )

Kim, W y Mauborgne, R. (2005). La Estrategia del Océano Azul. Buenos Aires: Editorial: Norma.

Klein, N. (2002). No logo, Buenos Aires: Paidós.

La Voz. Facebook pierde usuarios en EE.UU, Canadá y Reino Unido. Recuperado el 14 de junio de 2012 de http://www.lavoz.com.ar/noticias/tecnologia/facebook-pierde-usuarioseeuu-canada-reino-unido

Las pérdidas de Facebook. (recuperado el 14 de junio de 2012 de http://www.maspixel. com/2012/03/las-perdidas-de-facebook/)

Ledesma, M. (2003). El Diseño Gráfico, una voz pública (de la comunicación visual en la era del individualismo). Buenos Aires: Editorial Argonauta.

Manrique, J. (2002). Poesía. Barcelona: Editorial Debolsillo.

Obiols, G. (1985). Curso de Lógica y Filosofía. Buenos Aires: Kapelusz.

Ortega y Gasset, J. (1930). La rebelión de las masas, Madrid: Revista de Occidente.

Pol, A. (2005) Secretos de marcas, logotipos y avisos publicitarios. Simbolismo gráfico, espacial y cromático. Buenos Aires: Dunken.

Satué, E. (1994). Historia del diseño gráfico desde sus orígenes hasta nuestros días. Barcelona: Paidós.

Valdés de León, G. (2010). Tierra de nadie. Una molesta introducción al estudio del Diseño, Buenos Aires: Universidad de Palermo. Facultad de Diseño y Comunicación. Centro de Estudios en Diseño y Comunicación.

Vázquez, G. (2012). Jot Down Cultural Magazine, El imbécil digital (Recuperado el 28/02/2012 de http://www.jotdown.es/2012/02/gonzalo-vazquez-el-imbecil-digital/)

Wilensky, A. (2003). La promesa de la marca, Capítulos 11 y 12, Buenos Aires: Temas.

Summary: For large companies and the current leading brands, 2020 is the near future, in terms of strategy and trends. In view of the new decade, we believe that the main value 
for management in order to efficiently "conceive and manage a brand" is not merely cognitive but attitudinal; the role of the brand manager wins an unprecedented shift from traditional brand manager, to a kind of brand trend hunter that monitors the market in a creative and holistic way.

We address the construction of a map of baseline scenarios for 2020 brands, starting a chain of significant events and revealing features of our near future, in terms of branding.

Key words: branding - prospective - brand management - brand trend hunter - brands trendy scenarios - insight.

Resumo: Para as grandes empresas e as marcas líderes atuais, o ano 2000 já é o futuro próximo, em términos estratégicos e tendenciais. Em vistas ao novo decênio, consideramos que o valor gerencial determinante, à hora de "gestar e administrar uma marca" com eficiência, não é de caráter meramente cognitivo senão atitudinal; o papel do brand manager sofreu uma inédita deslocação, desde o tradicional gerente de marca, até uma espécie de brand trend hunter (caçador de tendências de marca) que monitora o mercado de modo criativo e holístico.

Abordamos a construção de um mapa de cenários tendenciais para as marcas 2020, a partir de um encadeamento de fenômenos significativos e características reveladoras de nosso futuro próximo, em matéria de branding.

Palavras chave: branding - prospectiva - gestão marcaria - brand trend hunter - marcas cenários tendenciais - insight. 